\title{
PhD supervision in Public Health
}

\author{
Pramod R. Regmi ${ }^{*}$, Amudha Poobalan ${ }^{2}$, Padam Simkhada ${ }^{3}$, Edwin van Teijlingen ${ }^{4}$ \\ ${ }^{1}$ Faculty of Health and Social Sciences, Bournemouth University, UK; Visiting Fellow, Chitwan Medical College, Nepal and Datta Meghe Institute of Medical Sciences, India \\ ${ }^{2}$ School of Medicine, Medical Sciences and Nutrition, University of Aberdeen, UK \\ ${ }^{3}$ School of Human and Health Sciences, University of Huddersfield, UK; Visiting Professor, Manmohan Memorial Institute of Health Science, Nepal and Nobel College, \\ Nepal \\ ${ }^{4}$ Faculty of Health and Social Sciences, Bournemouth University, UK; Visiting Professor, Manmohan Memorial Institute of Health Sciences, Nepal and Nobel College, \\ Nepal
}

Received:

6 November 2020

Revised:

14 January 2020

Accepted:

3 February 2021

${ }^{*}$ Corresponding author

pregmi@bournemouth.ac.uk

\begin{abstract}
Roles of $\mathrm{PhD}$ supervisors are diverse, ranging from providing in-depth discipline-specific Public Health knowledge and technical (e.g., methodological) support to the students, encouraging them towards publications or conference presentations, offering pastoral support for student wellbeing, and finally preparing them to defend their thesis by conducting a mock viva. Effective supervision plays a vital role in a $\mathrm{PhD}$ journey reflecting on the quality of the $\mathrm{PhD}$ work, positive $\mathrm{PhD}$ experience, and supervisor-student relationship. While some student-supervisors team may encounter conflicting and challenging relationships, many relationships between $\mathrm{PhD}$ supervisor(s) and students progress into mentorship through joint publications and grant applications, career advice and support establishing wider collaborative networks. Drawing from the wider experiences of the authors, this article highlights the responsibilities, opportunities, and sometimes the challenging nature of being a $\mathrm{PhD}$ supervisor. This reflection will inform good practices for $\mathrm{PhD}$ supervisors in countries including Nepal, where the numbers of $\mathrm{PhD}$ students in the field of Public Health is steadily increasing.
\end{abstract}

Keywords: PhD supervision, Supervisory roles, Academic relationships, PhD Viva

Tweetable abstract: PhD supervision in Public Health is growing in importance in Nepal

\section{Introduction}

Public Health is a truly multi and interdisciplinary [1] subject, which incorporates a wide range of disciplines, namely from Medicine, Statistics, Behavioural Science to Social Sciences and Ethics. Public Health is also a very practical discipline underpinned by research and education. While some work in professional practice as Public Health practitioners and officers or as nurses and doctors in disease control, others work as Public Health academics predominantly in research or education.

Undertaking a $\mathrm{PhD}$ is the highest qualification in most disciplines, with a scholarly piece of research output that establishes a student as an independent researcher. Given the multidisciplinary nature of Public Health PhDs, it is usually supervised by two, occasionally three, PhD supervisors (also called advisors in North America). The authors of this paper cumulatively have supervised over 60 PhD students at seven different universities in the UK (United Kingdom), where students are either from the UK or from other LMIC (Low- and Middle-Income Countries) studying at UK universities. They have also examined many Public Health doctoral theses in Europe (mainly the UK, but also Denmark, Finland, the Netherlands, Belgium, Ireland), Australia and Nepal. While requirements regarding a PhD are universal, regulations concerning the format of the thesis, maximum word length, etc. vary between countries, universities and disciplines. Ultimately the key requirements for a $\mathrm{PhD}$ are that the research thesis is based on (a) original work which makes (b) a significant contribution to existing knowledge. This article highlights the responsibilities of a Public Health academic (university faculty) as a PhD supervisor to help the students achieve the key requirements, while highlighting the potential challenges and solutions.

\section{The multiple roles of a $\mathrm{PhD}$ supervisor}

The key aim of the supervisors is to guide and motivate the $\mathrm{PhD}$ student to become a confident skilled researcher. To achieve this aim, a PhD supervisor has several overlapping tasks [2]. It is usually expected that a proposed supervisor has a PhD. However, this is not always a very strict requirement, especially if there is a team of supervisors. PhD students, typically, will have two or three supervisors. In several countries, but not everywhere, a dedicated member of staff will oversee the administrative and regulatory part of the research process called the 'Director of Studies'. They are responsible for making sure the students have adequate resources and support to achieve the goal. Sometimes they take on the role of lead supervisors. The first or lead supervisor typically guides the student through the entire research process. The second supervisor provides the additional subject and/or methodological expertise. In some disciplines, such as Public Health or Arts-based disciplines, second (or third) supervisors are appointed because they bring a practice perspective, and they may not have their $\mathrm{PhD}$.

Supervisors are not only experts who have a strong understanding in the research field, but they also facilitate emotional processes when required or provide mentorship to guide a student throughout the developmental phase into becoming an independent researcher. 
A good supervisor should be able to create and stimulate an appropriate intellectual climate for the $\mathrm{PhD}$ student. A good supervisory relationship with the postgraduate student is key to their success [3]. Consequently, the question is "What makes a good supervisor and how this can be sustained as a good supervisory relationship in Public Health?"

A study by Ali et al. [4] reported a consensus between students and supervisors highlighting the attributes of effective supervision. These attributes included the supervisor's keen interest in the postgraduate research (PGR) student's research, providing timely and constructive feedback, and help students to manage time effectively. They should help students where limitations and learning needs are identified [4]. Similarly, Tahir and colleagues [5] suggest three different key attributes of supervisors, where they should be friendly, approachable, and flexible; knowledgeable and resourceful; and encourage students to work and plan independently.

Public Health PhDs usually lend themselves to a multidisciplinary supervisory team, where each supervisor may have a different role within different supervisory teams. For example, sometimes a supervisor may act as the country or context expert or the qualitative research expert, yet on other supervisory teams, the same person may be the health service researcher, or the mixed-methods expert or the interdisciplinary expert. The specific role of a supervisor within a team has to suit the student's needs, recognise their strengths, but also the strengths and weaknesses of co-supervisors on the team [6].

Supervisors constantly have to negotiate the dual role of assessor and a guide [7], which potentially could cause tension between being the supportive supervisor, and ensuring the thesis reaches the required university standards. To keep up the academic standards, the role of a supervisor is to motivate the postgraduate research students to write for publication, encouraging students to get started early with drafting a paper [8] and/or an abstract for an academic conference [9]. It is important to treat students as independent adult learners, play to their strengths and help them overcome individual weaknesses. Not only is every student different, but also each PhD project is unique. Managing the academic expectations, while being supportive; allowing students to be curious to explore further afield but also to reign them in to keep the focus of the $\mathrm{PhD}$ is a delicate balance, which brings effective supervision to the fore. However, students suggest that important positive characteristics of supervisors include being professional and pleasant and showing supportive behaviour [10]. Often students need very specific hands-on support, for example when they are preparing their research ethics application or draft conference abstract at the onset of their PhD journey. Students doing fieldwork abroad need ethical approval from the university of study and an institution in the fieldwork country [11,12]. Most students will never have prepared a research ethics application or have faced an ethics panel and a supervisor's task is to guide and support them through complicated and often bureaucratic procedures.

\section{Negotiating contextual challenges}

Multidisciplinary Public Health PhDs, especially those that cross boundaries need to negotiate cultural and hierarchical sensitivities. Supervisors play a key role in helping students navigate these challenges. Generally, students from some cultural contexts (e.g. Nepal, India, China) have great respect for authority, which stops them from critiquing/challenging a supervisor and defending their work in supervisory meetings. This can be a cultural issue in large parts of South Asia. Reflecting on this, the role of the supervisor is to evoke curiosity by asking more qualitative questions such as: 'What would you do to solve this?' or 'What do you think is the problem?' or 'Where would you go from here?' Using these open questions encourages the students to assess the motivation which had brought them to the point of applying to complete a $\mathrm{PhD}$ and have the confidence to express their ideas. This also helps them to gain confidence and realise the expertise on their country and culture and consequently develop research skills and expertise. PhDs can sometimes evolve and can unsettle students. Training students to be aware of the potentially changing reality within a $\mathrm{PhD}$ can be crucial in a supervisory role. Occasionally, supervisors could be drawn from different cultural and educational contexts and may approach the PhDs differently although within an overarching Public Health topic. Different approaches between supervisors can put students in a difficult situation. Being sensitive to these subtle differences will make supervising a pleasant experience.

\section{When things go wrong}

$\mathrm{PhD}$ is a long journey and effective communication throughout is a key to successful supervision [6], especially when things are not going too well for the student. This ranges from listening to the students carefully and also communicating with the co-supervisors effectively. Most $\mathrm{PhD}$ students are mature and may have many burdens in their private lives or they may face changes in their everyday lives throughout the $\mathrm{PhD}$ process due to events outwith their control. $\mathrm{PhD}$ students also come with different levels of research skills, as well as work experiences and communication styles, professional expertise, and personalities. Supervision can then become a delicate balance between teaching and guiding while retaining one's respect for the student. Mutual respect in which the learning can happen can be achieved by effective communication.

Despite most supervisors being well-motivated, sometimes they contribute too little, they may simply be too busy with other commitments. Perhaps less common is the $\mathrm{PhD}$ supervisor who contributes 'too much', i.e. trying the make the student's PhD research their own. Culture can be a barrier here. When things go wrong cultural factors may make it far more difficult for $\mathrm{PhD}$ students to express their concerns and anxieties. However, they may similarly make it more difficult for a supervisor to acknowledge their problems.

Since doing a $\mathrm{PhD}$ takes at least three years, and occasionally much longer, supervisors may move to another institution while the student continues the $\mathrm{PhD}$ at the original university. In many cases, supervisors wish to continue the supervision remotely. However, in some cases, host universities arrange a new supervisor or if there is a co-supervisor, roles can be swapped. Besides, relationships between $\mathrm{PhD}$ student and supervisor can be or become complex. In some cases, student-supervisor relationships break down due to conflicting personalities, working styles, unique supervisory style and expectations, or poor student-supervisor communications. It is thus very useful 
to start a conversation early enough to understand working style or set out expectations. Universities may have different approaches to resolving these issues when the student-supervisor relationship goes wrong. We recommend that when issues arise, students share these issues with their supervisors and relevant postgraduate colleagues (e.g. the university's postgraduate research coordinator). As much as possible discuss issues to find an appropriate solution.

\section{Preparing the student for the examination}

Ultimately the role of the supervisor is to fine-tune the students' research ability to the desired level to defend the scholarship which will establish them as independent researchers. The $\mathrm{PhD}$ examination is called a viva. $\mathrm{PhD}$ candidates may have odd preconceptions or unfortunate expectations of what a viva constitutes [13]. Such confusion is understandable since the $\mathrm{PhD}$ examination differs in different countries. In many Nordic countries, Belgium and the Netherlands the draft thesis is reviewed by a team of internal and external examiners before the viva. The PhD student receives a set of written comments from each examiner and incorporates these suggestions in the final thesis. The final thesis is printed before the final public examination which is more a celebratory event than a real examination. In the $\mathrm{UK}$, the $\mathrm{PhD}$ viva is very much a real exam, whereby the $\mathrm{PhD}$ student (called the candidate) is examined for several hours on all aspects of the research and the thesis. In most cases, the PhD student is asked to rewrite some selected parts of the thesis, which might need more clarification. Students may also be asked to do more fieldwork, more analysis, bring in specific theories, and/or update the literature.

Therefore, the roles of the supervisors are to ensure that students have done a mock viva to prepare them. In a small study of UK PhD candidates, $90 \%$ found that mock viva was helpful [14]. Our experience is very similar to the experienced examiners interviewed by Mullins and Kiley [15] who argued that one or more published papers included in the thesis do affect the perceptions of the examiners. If the $\mathrm{PhD}$ student has published at least one peer-reviewed paper this is likely to influence the examiners into thinking "other academics have reviewed the study and accepted it for publication, therefore it can't be too bad." Many students (and academics) do not realise that writing a scientific paper for publication is different from writing a $\mathrm{PhD}$ chapter.

Of course, some countries accept a $\mathrm{PhD}$ thesis comprising of already published articles. For example, in many Nordic countries, Belgium and the Netherlands the thesis includes an Introduction chapter, four or five published papers, and two chapters at the end; the Discussion and Conclusion. The papers will have been written in the style required by the individual academic journal and only the Introduction and Discussion and Conclusion are specifically written for the thesis.

Working with PhD students, we see our role as a supervisor partly motiving the PGR students to write for publication and hence to get started with drafting a paper [8].

\section{A 'never-ending' relationship?}

Supervisors and their PhD students may never see or speak again after the $\mathrm{PhD}$ completion. In most cases, however, the relationship between supervisor and student after $\mathrm{PhD}$ continues. They become an academic friend and mentor for a lifetime. We have been working with many of our PhD students after their PhDs. Joint publications and grant applications are the most common platform to sustain an academic relationships. For example, EvT, PS, and PR between them have more than 50 publications and several joint grant applications. PR completed his PhD under the supervision of EvT and PS a decade ago. Clear email communication, regular participation in professional meetings or conferences, or staying in touch via research and social networking sites sustains the relationships. PhD supervisors often end up giving career advice to their former students, writing job/promotion references for them, inviting them on editorial boards of journals, and so on. For students, having a good working relationship with their supervisors can improve their chances of securing a postdoctoral job or an academic grant.

Three of us are editors of academic journals in Nepal as well as international ones. We encourage our PhD students to act as a reviewer as a way of learning about the review process, what Green and colleagues called: 'secrets of the trade' [16]. The experience of being a reviewer helped the authors to understand how to assess the work of others and provide constructive criticism, whilst at the same time gain an understanding of how others (i.e. examiners) may assess a scientific paper.

\section{Supervisor recognition}

Over the past three decades, universities have recognised that $\mathrm{PhD}$ students often need training over and above academic supervision $[7,17]$. The process of doing a $\mathrm{PhD}$ has become much more professionalised [18] as 'transferrable skills programmes' have been introduced by universities to include, for example, presentation skills, preparation for job interviews, learning to apply for grants, and academic publishing.

The UK has also recognised this need for supervisory training and support and established the UKCGE (UK Council for Graduate Education). Recently (2020), it established a Research Supervisors Network which is the world's first national network for research supervisors [https://supervision.ukcge.ac.uk/good-supervisory-practice-framework/]. EvT received the accolade 'UKCGE Recognised Research Supervisor' in early 2021. As far as the authors are aware, there is no such supervisory network with formal recognition in South Asia.

\section{Conclusion}

Effective doctoral supervision is a most important factor for determining the success of a quality $\mathrm{PhD}$ study, promoting a positive learning experience for the student and the enjoyment of doing a $\mathrm{PhD}$. Roles of $\mathrm{PhD}$ supervisors are not only confined to offering $\mathrm{PhD}$ topic or methods-related guidance but also to provide wellbeing or mentoring support. Multiple roles of PhD supervisors are widely 
acknowledged, and many factors influence supervisor-student relationships. To build a good relationship between $\mathrm{PhD}$ supervisors and students, together with good communication, understanding the working styles of supervisors and expectations of supervisors and students should be established at the outset. With the growing number of Public Health PhD students in several countries, including Nepal, it is crucial that the training and the support needs of the $\mathrm{PhD}$ supervisors are recognised. The good practices, challenges, and potential solutions presented in this article could help universities in Nepal to build pedagogical leadership within the country.

\section{Competing interests}

The authors declare that they have no competing interests.

\section{References}

1. van Teijlingen E, Regmi P, Adhikary P, Aryal N, Simkhada P. Interdisciplinary Research in Public Health: Not quite straightforward. Health Prospect. 2019;18(1): 4-7.

2. Gill P, Burnard P. The student/supervisor relationship in the PhD/doctoral process. Br J Nurs. 2008; 17:668-671.

3. Orellana M, Darder A, Pérez A, Salinas J. Improving Doctoral Success by Matching PhD Students with Supervisors. Int J Doctoral Stud.2016;11; 87-103.

4. Ali PA, Watson R, Dhingra K. Postgraduate research students' and their supervisors' attitudes towards supervision. Int J Doctoral Stud. 2016;11: 227-241.

5. Tahir, IM, Ghani, NA, Atek, ESE, Manaf ZA. Effective Supervision from Research Students' Perspective. Int J Educ.2012; 4 (2):211-222.

6. Taylor S, Beasley N. A Handbook for Doctoral Supervisors. London: Routledge Falmer; 2005.

7. Murphy N, Bain, JD, Conrad LM. Orientations to research higher degree supervision. Higher Educ. 2007;53(2): 209-34.

8. van Teijlingen, E, Simkhada, PP, Rizyal A. Submitting a paper to an academic peer-reviewed journal, where to start? Health Renaissance. 2012;10(1): 1-4.

9. Simkhada P, van Teijlingen E, Hundley V, Simkhada BD. Writing an Abstract for a Scientific Conference. Kathmandu Univ Med J. 2013;11(3): 262-65.

10. Seagram BC, Gould J, Pyke W. An investigation of gender and other variables on time to completion of doctoral degrees. Res Higher Educ. 1998;39(3): 319-35.

11. Regmi PR, Aryal N, Kurmi O, Pant PR, van Teijlingen E,Wasti SP. Informed consent in health research: challenges and barriers in low-and middle-income countries with specific reference to Nepal. Dev World Bioethics. 2017;17(2):84-89.

12. van Teijlingen ER, Simkhada PP. Ethical approval in developing countries is not optional. J Med Ethics. 2012; 38:428-430.

13. Wellington J. Supporting students' preparation for the viva: their pre-conceptions and implications for practice. Teach Higher Educ. 2010;15(1): 71-84.

14. Hartley J, Fox C. Assessing the mock viva: the experiences of British doctoral students. Stud Higher Educ. 2004; 29(6):727-738.

15. Mullins G, Kiley M. 'It’s a PhD, not a Nobel Prize': How experienced examiners assess research theses, Stud Higher Educ. 2002; 27(4):369-86.

16. Green BN, Johnson CD, Adams A. Writing narrative literature reviews for peer-reviewed journals: secrets of the trade. J Chiropr Med. 2016;5(3):101-117.

17. Sverdlik A, Hall, NC, McAlpine L, Hubbard K. Journeys of a PhD student and unaccompanied minors. Int J Doctoral Stud. 2018;13: 361-388. https://doi.

org/10.28945/4113

18. Pearson M. Professionalising PhD education to enhance the quality of the student experience. Higher Educ.1996;32(3): 303-20. 